\title{
Does bronchography have a role in the assessment of patients with haemoptysis?
}

\author{
DK JONES, P CAVANAGH, JM SHNEERSON, CDR FLOWER
}

From the Departments of Radiology and Chest Medicine, Papworth Hospital, Cambridge

ABSTRACT The results of bronchography in 96 consecutive patients investigated for haemoptysis at Papworth Hospital from 1975 to 1983 were reviewed. None of the patients included in this study gave a history suggestive of bronchiectasis and neither chest radiography nor fibreoptic bronchoscopy had shown a cause for the bleeding. Bronchography was performed through the fibreoptic bronchoscope and all included in the study showed both lungs adequately. The chest radiographic appearances were compared with the bronchographic findings. Seven of 12 patients with appearances suggesting old fibrosis showed bronchiectasis, as did eight of 10 with radiographic appearances suggestive of bronchiectasis. Eleven out of 74 patients with normal chest radiographs, however, also showed bronchiectasis. This group of 11 was compared with the other 63 but no clinical feature was found to be significantly associated with the presence of bronchiectasis. Although bronchography is now rarely used in the investigation of haemoptysis, this high yield $(15 \%)$ of bronchiectasis indicates that its use should be reappraised. Follow up of the patients indicated that bronchography was not reliable at diagnosing peripheral bronchial carcinomas, which became evident later in two cases, and that asthma was present in $15(24 \%)$ of the 63 patients with both normal chest radiographs and normal bronchograms.

The patient who presents with haemoptysis as the major symptom poses a difficult problem for the investigating physician. After a full history, clinical examination, chest radiography and fibreoptic bronchoscopy, no cause is found in over half of the patients.' There has been a decline in the use of bronchography in recent years, due largely to a reduction in the prevalence of bronchiectasis. It has been held to be of limited use in the investigation of patients presenting with haemoptysis. ${ }^{2}$ Over the past nine years we have used bronchography as an adjunct to fibreoptic bronchoscopy in the investigation of patients presenting with haemoptysis. To evaluate the usefulness of this procedure we have carried out a retrospective analysis of our results.

\section{Subjects and methods}

We reviewed the case records of all patients who had undergone bronchography from 1975 to 1983 for the investigation of haemoptysis. Patients

Address for reprint requests: Dr DK Jones, Chest Unit, Papworth Hospital, Papworth Everard, Cambridge CB3 8RE.

Accepted 13 March 1985 included in the study were those in whom a clinical history and examination did not suggest bronchiectasis as a cause for their haemoptysis and in whom the chest radiograph and fibreoptic bronchoscopy had shown no evidence of neoplasm. In addition, the bronchograms had adequately outlined the whole bronchial tree. Our method of performing bronchography has been described in detail elsewhere. ${ }^{3}$ In brief, the patient undergoes fibreoptic bronchoscopy via the nasal route lying on a tilting fluoroscopic table. At the end of the bronchoscopic examination a thin polyethylene cannula is passed down the suction channel of the instrument and positioned in the appropriate bronchus under direct vision. While the cannula is manipulated under fluoroscopic control, aqueous propyliodone is instilled into each of the lobar bronchi. About $30-40 \mathrm{ml}$ of contrast medium are required for bilateral bronchography.

Posteroanterior and lateral chest radiographs had been taken just before bronchography in each patient. These were randomly mixed with an equal number of normal chest radiographs selected from patients attending the chest unit for other reasons. The radiographs were reviewed in a blind fashion by 
Table 1 Relationship between chest radiographic appearances and presence or absence of bronchiectasis

\begin{tabular}{|c|c|c|c|c|}
\hline \multicolumn{2}{|c|}{$\begin{array}{l}\text { Chest radiograph } \\
\text { classification }\end{array}$} & $\begin{array}{l}\text { Total } \\
\text { No } \\
74\end{array}$ & $\begin{array}{l}\begin{array}{l}\text { No (\%) } \\
\text { without } \\
\text { bronchi- } \\
\text { ectasis }\end{array} \\
63(85)\end{array}$ & $\begin{array}{l}\begin{array}{l}\text { No }(\%) \\
\text { with } \\
\text { bronchi- } \\
\text { ectasis }\end{array} \\
11(15)\end{array}$ \\
\hline & $\begin{array}{l}\text { Normal } \\
\text { Suggestive of bronchiectasis } \\
\text { Diagnostic of bronchiectasis } \\
\text { Fibrotic changes }\end{array}$ & $\begin{array}{r}74 \\
10 \\
0 \\
12\end{array}$ & $\begin{array}{l}63(85) \\
2(20) \\
0 \\
7(58)\end{array}$ & $\begin{array}{l}11(15) \\
8(80) \\
0 \\
5(42)\end{array}$ \\
\hline
\end{tabular}

a consultant chest radiologist (CDRF) and grouped in the following manner: Group 0-the chest radiograph was normal or had incidental abnormalities not suggestive of bronchiectasis. Group 1-the chest radiograph had changes suggestive (but not diagnostic) of bronchiectasis. Examples of these changes are slight crowding of vessels, blurring of vessel margins, bronchial wall thickening, and single tubular opacities. Group 2-the chest radiograph had changes diagnostic of bronchiectasis: for example, multiple tubular opacities, loss of lung volume, and ring shadows with or without fluid levels. Group 3 - the chest radiograph showed changes suggestive of old fibrosis with loss of lung volume and variable amounts of calcification consistent with previous infection with tuberculosis.

All normal control radiographs were correctly identified as group 0 . The chest radiographic findings were then compared with the bronchograms that had been reported at the time of their performance by the same consultant radiologist (CDRF).

\section{Results}

Ninety six patients fulfilled the criteria for entry into the study. Fifty four were male and 42 were female, and their ages ranged from 13 to 76 years with a mean of 45 years.

The bronchographic changes and the findings on the chest radiographs are shown in table 1 . Almost half of the patients in group $3 \mathrm{had}$ an area (or areas) of bronchiectasis. These were found exclusively in the fibrotic zones shown on the chest radiograph. No

Table 2 Clinical details and distribution of bronchiectasis (B) in 11 patients with grade 0 (normal) chest radiograph and bronchographic evidence of bronchiectasis

\begin{tabular}{ll}
\hline No of patients & 11 \\
Age range & $18-70 \mathrm{y}$ \\
Mean age & $43 \mathrm{y}$ \\
Male:female & $6: 5$ \\
B confined to one segment & 2 \\
B in more than one segment of one lobe & 5 \\
B in segments of two lobes of one lung & 1 \\
B in basal segments of both lungs & 3 \\
\hline
\end{tabular}

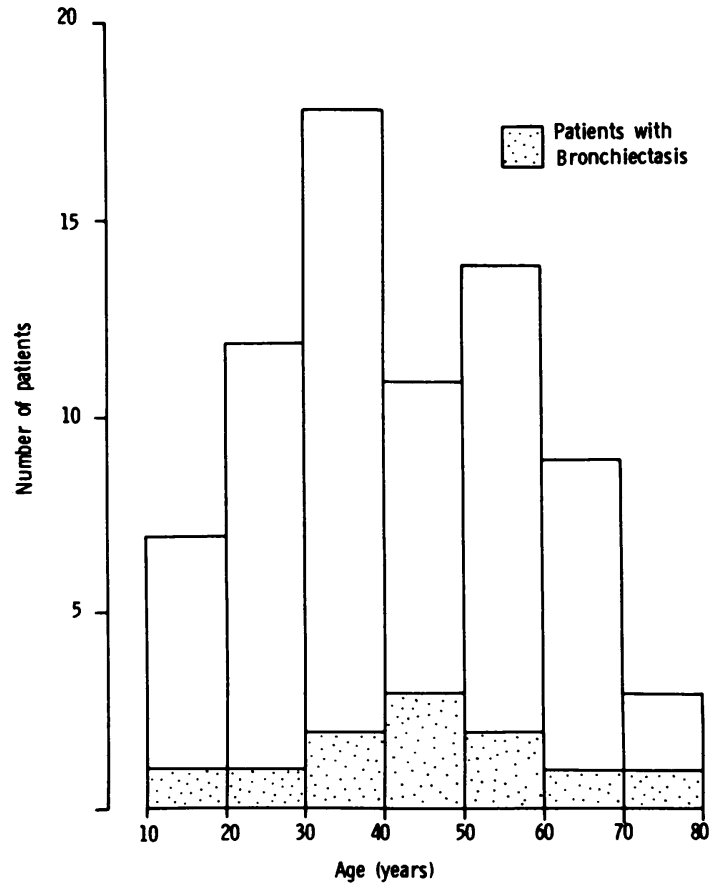

Age distribution of 63 patients with grade 0 (normal) chest radiographs with and without bronchiectasis demonstrable by bronchography.

patients in group 2 were found in the study. This was not surprising as patients with definite radiographic changes usually give a typical clinical history of bronchiectasis. Eight of the 10 patients in group 1 had bronchiectasis.

Of the 74 patients in group $0,11(15 \%)$ had bronchiectasis demonstrated by bronchography (table 2 ). We reviewed and compared the case histories of these 11 patients with those of 63 patients in the same group who had normal bronchograms in an attempt to identify any features that might allow prediction of the presence of bronchiectasis. In particular, we noted the following features: sex distribution; age (figure); number of smokers in each group; number of patients with a history of a previous significant chest illness; number of patients with a chronic cough productive of mucoid sputum; number of patients investigated for a single haemoptysis; number of patients investigated for repeated haemoptysis; number of patients who had had a haemoptysis more than one year before the haemoptysis investigated; and number of patients who had a cough productive of purulent sputum at the time of their haemoptysis.

There were no significant differences in any of 
Table 3 Final diagnosis reached in 63 patients with grade 0 (normal) chest radiograph in whom there was no bronchographic evidence of bronchiectasis

Total No of patients

No diagnosis reached

Asthma

Acute bronchitis

Upper respiratory tract infection

Carcinoma of the bronchus

Hereditary haemorrhagic telangiectasia

these features between the two groups using $\chi^{2}$ analysis with Yates's correction.

The group of 63 patients with haemoptysis and normal bronchograms were followed up for a mean period of eight months (range one month to three years). The final diagnoses are shown in table 3 .

\section{Discussion}

In 1967 a report by the American College of Physicians stated that the investigation of haemoptysis was the second most common reason for the performance of bronchography. ${ }^{4}$ Since then, however, it has become generally believed that this investigation is of little use when the chest radiograph is normal. ${ }^{2}$ A previous study similar to ours ${ }^{5}$ showed a much lower incidence of bronchiectasis $-2 \%$ of patients with a normal chest radiograph and haemoptysis were found to have bronchiectasis on bronchography. Not all of the patients, however, had undergone full bilateral bronchography. Our study shows a $15 \%$ incidence of bronchiectasis among patients with chest radiographic appearances not suggestive of bronchiectasis. Two of the 11 patients did have transient shadows indicating consolidation on previous radiographs in areas in which bronchiectasis was finally demonstrated and one patient had a previous radiograph taken at the time of a large haemoptysis showing widespread alveolar shadowing consistent with aspirated blood. Eight of the patients had never had any radiographic abnormalities.

Most of our patients could be regarded as having small areas of "dry" bronchiectasis. As seen from table 2, most had bronchiectasis confined to one lobe or segment. Classically, bronchiectasis manifests itself by a chronic productive cough. Most such patients have abnormalities on their chest radiographs $^{6}$ that enable the diagnosis to be made without bronchography. This clinical presentation is becoming much less common and the proportion of patients with bronchiectasis presenting with haemoptysis and a normal chest radiograph may be increasing.

The technique of bronchography via the fibreoptic bronchoscope as described by us $^{3}$ is less distressing for patients than traditional techniques and can be readily performed at the same time as the bron- choscopy. We believe that it is valuable in demonstrating focal areas of bronchiectasis as the cause of otherwise unexplained haemoptysis in an appreciable number of patients. We previously considered that patients under 40 with haemoptysis and a normal chest radiograph did not merit bronchography. ${ }^{3}$ This larger and more specific study shows, however, that it is of diagnostic value even in this age group.

Even after bronchoscopy and bronchography the cause of a patient's haemoptysis is often not known (table 3). Fifteen of our patients in this group had asthma diagnosed either before or shortly after the haemoptysis. Vascular congestion of the bronchial submucosa has been demonstrated in asthma ${ }^{7}$ and this hyperaemia may predispose to haemoptysis.

Bronchography seems to be valuable in demonstrating bronchiectasis, although we have not studied the effect of making this diagnosis on the subsequent management of the patients. The decision to proceed to surgery depends on the subsequent severity and frequency of the haemoptysis as well as a knowledge of its cause, but even if no active treatment is instituted it may be valuable for reassuring the patient of the cause of the bleeding.

Bronchial carcinomas were subsequently found after intervals of four months and two years in two of the 63 patients in whom no abnormality was found either from the original bronchoscopy or from bronchography. This confirms the commonly held view that bronchography is a poor way of identifying early carcinomas, which presumably cause only minor bronchial mucosal irregularities. It also emphasises that bronchography without bronchoscopy is not a sufficient investigation for the patient with unexplained haemoptysis.

We would like to thank Drs J E Stark and T W Higenbottam for their advice and for allowing us to study their patients. We also thank Miss S Smyth for secretarial assistance.

\section{References}

1 Mitchell DM, Stokes TC. Diagnostic methods in chest disease. Part 2. Hospital Update 1980;6:285-99.

2 Fraser RG, Paré JAP. Diagnosis of diseases of the chest. Vol 1. Philadelphia: WB Saunders, 1977:211-3.

3 Flower CDR, Shneerson JM. Bronchography via the fibreoptic bronchoscope. Thorax 1984;39:260-3.

4 American College of Chest Physicians. Bronchography: report of Committee of Broncho-esophagoscopy. Dis Chest 1967;51:663-8.

5 Forrest JV, Sagel SS, Omell GH. Bronchography in patients with haemoptysis. Am J Roentgenol 1976; 126: 597-600.

6 Gudbjerg CE. Roentgenologic diagnosis of bronchiectasis: analysis of 112 cases. Acta Radiol 1955;43:20926.

7 Heath D, Kay M. Bronchial asthma. In: Anderson JR, ed. Muir's Textbook of pathology. 11 th ed. London: Arnold, 1980:441-3. 